\title{
Randomized Trial of Oxygen Saturation Targets during and after Resuscitation and Reversal of Ductal Flow in an Ovine Model of Meconium Aspiration and Pulmonary Hypertension
}

 \\ 1 Department of Stem Cell Research, University of California, Davis, Sacramento, CA 95817, USA; \\ allesneski@ucdavis.edu \\ 2 Department of Pediatrics, University of California, Davis, Sacramento, CA 95817, USA; \\ pvali@ucdavis.edu (P.V.); mehardie@ucdavis.edu (M.E.H.); dsankaran@ucdavis.edu (D.S.) \\ * Correspondence: slakshmi@ucdavis.edu
}

Citation: Lesneski, A.L.; Vali, P.; Hardie, M.E.; Lakshminrusimha, S.; Sankaran, D. Randomized Trial of Oxygen Saturation Targets during and after Resuscitation and Reversal of Ductal Flow in an Ovine Model of Meconium Aspiration and Pulmonary Hypertension. Children 2021, 8, 594. https://doi.org/ 10.3390 /children 8070594

Academic Editor:

Bernhard Schwaberger

Received: 9 June 2021

Accepted: 12 July 2021

Published: 14 July 2021

Publisher's Note: MDPI stays neutra with regard to jurisdictional claims in published maps and institutional affiliations.

Copyright: (c) 2021 by the authors. Licensee MDPI, Basel, Switzerland. This article is an open access article distributed under the terms and conditions of the Creative Commons Attribution (CC BY) license (https:// creativecommons.org/licenses/by/ $4.0 /)$.

\begin{abstract}
Neonatal resuscitation (NRP) guidelines suggest targeting $85-95 \%$ preductal $\mathrm{SpO}_{2}$ by 10 min after birth. Optimal oxygen saturation $\left(\mathrm{SpO}_{2}\right)$ targets during resuscitation and in the postresuscitation management of neonatal meconium aspiration syndrome (MAS) with persistent pulmonary hypertension (PPHN) remains uncertain. Our objective was to compare the time to reversal of ductal flow from fetal pattern (right-to-left), to left-to-right, and to evaluate pulmonary ( $\mathrm{Q}_{\mathrm{PA}}$ ), carotid (QCA) and ductal ( $\mathrm{Q}_{\mathrm{DA}}$ ) blood flows between standard (85-94\%) and high (95-99\%) $\mathrm{SpO}_{2}$ targets during and after resuscitation. Twelve lambs asphyxiated by endotracheal meconium instillation and cord occlusion to induce MAS and PPHN were resuscitated per NRP guidelines and were randomized to either standard (85-94\%) or high (95-99\%) $\mathrm{SpO}_{2}$ targets. Out of twelve lambs with MAS and PPHN, six each were randomized to standard and high $\mathrm{SpO}_{2}$ targets. Median [interquartile range] time to change in direction of blood flow across the ductus arteriosus from right-to-left, to left-to-right was significantly shorter with high $\mathrm{SpO}_{2}$ target (7.4 (4.4-10.8) min) compared to standard $\mathrm{SpO}_{2}$ target (31.5 (21-66.2) $\mathrm{min}, p=0.03)$. Q $\mathrm{PA}$ was significantly higher during the first $10 \mathrm{~min}$ after birth with higher $\mathrm{SpO}_{2}$ target. At 60 min after birth, the $\mathrm{Q}_{\mathrm{PA}}, \mathrm{Q}_{\mathrm{CA}}$ and $\mathrm{Q}_{\mathrm{DA}}$ were not different between the groups. To conclude, targeting $\mathrm{SpO}_{2}$ of $95-99 \%$ during and after resuscitation may hasten reversal of ductal flow in lambs with MAS and PPHN and transiently increase QPA but no differences were observed at $60 \mathrm{~min}$. Clinical studies comparing low and high $\mathrm{SpO}_{2}$ targets assessing hemodynamics and neurodevelopmental outcomes are warranted.
\end{abstract}

Keywords: meconium aspiration; oxygen saturation targets; neonatal resuscitation; persistent pulmonary hypertension of the newborn; asphyxia; ductus arteriosus; pulmonary blood flow; post-resuscitation

\section{Introduction}

Successful transition of the fetus to extrauterine life involves a rapid increase in pulmonary blood flow (QPA) during the first few breaths after birth, allowing the lungs to establish as the site of gas exchange. A failure of this transition can lead to persistent pulmonary hypertension of the newborn (PPHN), characterized by sustained elevation of pulmonary vascular resistance (PVR), right-to-left shunting of blood across the foramen ovale and ductus arteriosus, and reduced QPA [1]. These newborns experience severe respiratory distress and labile hypoxemia soon after birth.

Oxygen $\left(\mathrm{O}_{2}\right)$ mediates decrease in PVR after birth and has been used to correct the hypoxemia in PPHN, along with strategies to improve lung inflation with respiratory support [2,3]. Current neonatal resuscitation guidelines recommend initiating ventilation with $21 \% \mathrm{O}_{2}$ with subsequent $\mathrm{O}_{2}$ titration to target goal preductal pulse oximetry $\mathrm{O}_{2}$ saturation $\left(\mathrm{SpO}_{2}\right)$ ranges corresponding to the minute of life, to achieve $85-95 \% \mathrm{SpO}_{2}$ by 
10 min after birth. This strategy has been associated with optimal hemodynamics and gas exchange during resuscitation [4]. Rawat et al. reported that targeting 95-99\% $\mathrm{SpO}_{2}$ in the post-resuscitation period lowered PVR and improved cerebral $\mathrm{O}_{2}$ delivery, while targeting $85-89 \% \mathrm{SpO}_{2}$ increased PVR, and decreased $\mathrm{Q}_{\mathrm{PA}}$ and cerebral $\mathrm{O}_{2}$ delivery in a term ovine model of meconium aspiration syndrome (MAS) with PPHN [5]. However, flow across the ductus arteriosus ( $\mathrm{Q}_{\mathrm{DA}}$ ) was not evaluated in this study and ductal flow is a major contributor to $\mathrm{Q}_{\mathrm{PA}}[6]$. The optimal preductal $\mathrm{SpO}_{2}$ target range during resuscitation and post-resuscitation period that hastens reversal of shunting across the patent ductus arteriosus (PDA) from the fetal pattern to the postnatal pattern of left-to-right remains unknown.

We hypothesized that the time to reversal of shunting across the PDA is shorter with high $\mathrm{SpO}_{2}$ target of $95-99 \%$ compared to standard $\mathrm{SpO}_{2}$ target of $85-94 \%$. Our objective was to compare the time to reversal of shunt across the PDA from the fetal (right-to-left) to the postnatal (left-to-right) pattern between standard (85-94\%) and high (95-99\%) $\mathrm{SpO}_{2}$ target ranges during resuscitation and the post-resuscitation period in a term ovine asphyxiated model of MAS and PPHN. We also evaluated the changes in $\mathrm{Q}_{\mathrm{PA}}, \mathrm{Q}_{\mathrm{DA}}$ and carotid blood flow $\left(\mathrm{Q}_{\mathrm{CA}}\right)$, and gas exchange at $10 \mathrm{~min}$ and $60 \mathrm{~min}$ after birth between low and high $\mathrm{SpO}_{2}$ targets as secondary outcomes.

\section{Materials and Methods}

The protocol was approved by the Institutional Animal Care and Use Committee (IACUC, protocol \#20267) at the University of California Davis, CA, USA. This protocol involves a perinatal model of MAS and PPHN in term newborn lambs that has been extensively described previously [5,7]. All experiments were performed in accordance with animal ethical guidelines (ARRIVE) [8]. Time-dated near-term (139-141 days) gestation pregnant ewes from Van Laningham Farm (Arbuckle, CA, USA) underwent cesarean section following overnight fasting, after endotracheal intubation under general anesthesia with IV diazepam and ketamine, and inhaled $2 \%$ isoflurane, as previously described [9].

\subsection{Fetal Instrumentation}

The fetal lamb was partially exteriorized and intubated with a $4.5-\mathrm{mm}$ cuffed endotracheal tube (ETT), the lung fluid was passively drained by gravity, and the ETT was occluded to prevent entry of air. The lamb was instrumented under maternal anesthesia after subcutaneous bupivacaine infiltration. Catheters were inserted into the right carotid artery and right jugular vein for preductal arterial blood draws, invasive blood pressure and heart rate monitoring, and IV access respectively. A flow probe (Transonics, Ithaca, NY, USA) was placed around the left carotid artery to measure blood flow. A left thoracotomy was performed, and flow probes were placed around the left pulmonary artery and ductus arteriosus to measure blood flows. Subsequently, the thoracotomy and neck incisions were closed in layers. The baseline hemodynamics were recorded and arterial blood gases were obtained.

\subsection{Meconium Instillation, Asphyxia and Resuscitation}

Fetal lambs were asphyxiated following instrumentation by umbilical cord occlusion (by manual compression) for $5 \mathrm{~min}$ or until heart rate decreased below 40 beats per minute. Meconium ( $5 \mathrm{~mL} / \mathrm{kg}$ of $20 \%$ meconium suspended in ewe amniotic fluid) was simultaneously instilled into their endotracheal tube as previously described $[7,10]$. During asphyxiation, the lambs gasped and spontaneously aspirated the meconium into their lungs. The cord compression was released for 2 min to allow hemodynamic recovery, followed by another 5-min cord occlusion.

Lambs were randomized to standard $\mathrm{SpO}_{2}$ target (85-94\%) or high $\mathrm{SpO}_{2}$ target (95-99\%) using opaque envelopes prior to the beginning of the study (incision for cesarean section). The lambs were then delivered and ventilated with peak inflation pressures (PIP) of $30-35 \mathrm{~cm} \mathrm{H}_{2} \mathrm{O}$, PEEP of $5 \mathrm{~cm} \mathrm{H}_{2} \mathrm{O}$, rate of 40 breaths per minute and inspired $\mathrm{O}_{2}$ of $21 \%$ 
that was then titrated based on preductal $\mathrm{SpO}_{2}$ per Neonatal Resuscitation Program (NRP) guidelines during resuscitation to achieve a goal of 85-94\% (standard target arm) [11] or titrated to achieve a goal of $95-99 \% \mathrm{SpO}_{2}$ after delivery (high target arm). The titration of oxygen was proportional to the difference between observed $\mathrm{SpO}_{2}$ and target $\mathrm{SpO}_{2}$ and was performed every minute. The endotracheal tube was connected to a ventilator and $\mathrm{PaCO}_{2}$ was targeted in the $40-60 \mathrm{~mm} \mathrm{Hg}$ range to allow permissive hypercapnia. The resuscitators were not blinded to the intervention. Hemodynamics were continuously monitored, and arterial blood gases were obtained at baseline, 10-min and subsequently at 15-min intervals. Lambs were monitored for up to $60 \mathrm{~min}$ and were finally euthanized using IV pentobarbital (Fatal-Plus, Vortech Pharmaceuticals, Dearborn, MI, USA).

\subsection{Primary and Secondary Outcomes}

Primary outcome measures were time to reversal of ductal shunt (from right-to-left to left-to-right) from the time of delivery.

Secondary outcome measures were changes in $\mathrm{Q}_{\mathrm{PA}}, \mathrm{Q}_{\mathrm{DA}}$ and $\mathrm{Q}_{\mathrm{CA}}$, and gas exchange at $10 \mathrm{~min}$ and $60 \mathrm{~min}$ after birth between standard and high $\mathrm{SpO}_{2}$ targets. Cerebral oxygen delivery $(\mathrm{mL} / \mathrm{kg} / \mathrm{min})$ was calculated by multiplying carotid artery oxygen content $\left(\mathrm{CaO}_{2}=\left(1.34 \times\right.\right.$ Hemoglobin in $\left.\mathrm{g} / \mathrm{dL} \times \mathrm{SaO}_{2} \% / 100 \%\right)+\left(\right.$ partial pressure of $\mathrm{O}_{2}$ in mm $\mathrm{Hg} \times 0.0031))$ and left carotid artery blood flow $(\mathrm{mL} / \mathrm{kg} / \mathrm{min})$.

\subsection{Data Collection and Analysis}

Hemodynamic variables were continuously monitored and recorded using BIOPAC systems data acquisition software (Goleta, CA, USA). Blood gases were analyzed using a blood gas analyzer (Radiometer ABL90 FLEX, Denmark). By convention, the right-to-left direction of $Q_{\mathrm{DA}}$ was labeled as negative and left-to-right direction of $\mathrm{Q}_{\mathrm{DA}}$ was labeled as positive. Categorical data were analyzed using chi-squared test with Fisher's exact test as appropriate, parametric continuous data were analyzed using unpaired $t$-test, and changes in $Q_{D A}$ and $Q_{P A}$ over time were compared using repeated measures ANOVA. The median time to reversal of shunting (non-parametric) was compared between standard and high $\mathrm{SpO}_{2}$ targets using Wilcoxon rank sum test. Statistical significance was defined as $p<0.05$.

\section{Results}

Out of twelve near-term lambs that were asphyxiated, six were randomized to standard $\mathrm{SpO}_{2}$ target and the remaining six were randomized to high $\mathrm{SpO}_{2}$ target. Hemodynamic and arterial blood gas characteristics at fetal baseline prior to asphyxia were similar between the study groups (Table 1 ).

\subsection{Time to Reversal of Shunt across the PDA}

Median (interquartile range) time to transition from right-to-left to exclusive leftto-right shunting across the ductus arteriosus was significantly shorter with high $\mathrm{SpO}_{2}$ target (7.4 (4.4-10.8) $\mathrm{min}$ ) compared to standard $\mathrm{SpO}_{2}$ target (31.5 (12-66.2) $\mathrm{min}, p=0.03$, Figure 1). The mean $\mathrm{Q}_{\mathrm{DA}}$ (left-to-right) flow was increased with the high $\mathrm{SpO}_{2}$ targets from 0.5 to $10 \mathrm{~min}$ by ANOVA repeated measures. The $\mathrm{Q}_{\mathrm{DA}}$ significantly increased from fetal baseline to 5-min after birth in both standard and high $\mathrm{SpO}_{2}$ targets $(p<0.05)$ and decreased significantly by $60 \mathrm{~min}$ in high $\mathrm{SpO}_{2}$ target $(p<0.05)$. 
Table 1. Comparison of fetal baseline hemodynamic and arterial blood gas parameters and end-asphyxia hemodynamic parameters in a near-term ovine model of meconium aspiration syndrome (MAS) and persistent pulmonary hypertension (PPHN) randomized to standard (85-94\%) and high (95-99\%) preductal $\mathrm{SpO}_{2}$ target groups.

\begin{tabular}{|c|c|c|}
\hline Parameter & Standard $\mathrm{SpO}_{2}$ Target $(85-94 \%, \mathrm{n}=6)$ & High $\mathrm{SpO}_{2}$ Target $(95-99 \%, \mathrm{n}=6)$ \\
\hline Weight (kg) & $3.4 \pm 0.8$ & $3.3 \pm 0.4$ \\
\hline Gestational Age (days) & $139.7 \pm 0.7$ & $139.3 \pm 0.8$ \\
\hline \multicolumn{3}{|c|}{ Parameters at Fetal Baseline } \\
\hline Hemoglobin, $\mathrm{g} / \mathrm{dL}$ & $13.88 \pm 2.47$ & $11.93 \pm 1.52$ \\
\hline $\mathrm{pH}$ & $7.18 \pm 0.08$ & $7.19 \pm 0.06$ \\
\hline $\mathrm{PaCO}_{2}(\mathrm{~mm} \mathrm{Hg})$ & $74.73 \pm 12.58$ & $64.95 \pm 5.17$ \\
\hline $\mathrm{PaO}_{2}(\mathrm{~mm} \mathrm{Hg})$ & $22.08 \pm 6.22$ & $28.38 \pm 4.51$ \\
\hline Cerebral Oxygen Delivery $(\mathrm{mL} / \mathrm{kg} / \mathrm{min})$ & $4.26 \pm 2.17$ & $2.40 \pm 0.64$ \\
\hline Lactate $(\mathrm{mmol} / \mathrm{L})$ & $2.20 \pm 0.53$ & $2.37 \pm 0.96$ \\
\hline Heart Rate (bpm) & $155.17 \pm 21.95$ & $164.23 \pm 21.50$ \\
\hline Mean Arterial Blood Pressure (mm Hg) & $55.52 \pm 4.42$ & $61.11 \pm 3.8$ \\
\hline Mean Ductal Blood Flow (mL/kg/min) & $-125.89 \pm 64.77$ & $-84.33 \pm 36.09$ \\
\hline $\begin{array}{l}\text { Mean Pulmonary Artery Blood Flow } \\
\qquad(\mathrm{mL} / \mathrm{kg} / \mathrm{min})\end{array}$ & $25.21 \pm 8.25$ & $49.39 \pm 23.59$ \\
\hline Duration of Asphyxia (min) & $13.43 \pm 0.63$ & $15.32 \pm 1.82$ \\
\hline \multicolumn{3}{|c|}{ Parameters at End of Asphyxia } \\
\hline $\begin{array}{l}\text { Mean Carotid Artery Blood Flow } \\
\qquad(\mathrm{mL} / \mathrm{kg} / \mathrm{min})\end{array}$ & $24.0(5.5)$ & $21.2(4.4)$ \\
\hline Mean Ductal Blood Flow (mL/kg/min) & $-18.3(6.9)$ & $-15(7.7)$ \\
\hline $\begin{array}{l}\text { Mean Pulmonary Artery Blood Flow } \\
\qquad(\mathrm{mL} / \mathrm{kg} / \mathrm{min})\end{array}$ & $18.3(2.7)$ & $29.4(13.2)$ \\
\hline
\end{tabular}

Data presented as mean \pm standard deviation. Data were not different by unpaired $t$ test. $\mathrm{PaCO}_{2}=$ arterial carbon dioxide pressure; $\mathrm{PaO}_{2}=$ arterial oxygen pressure; $\mathrm{SpO}_{2}=$ oxygen saturation.

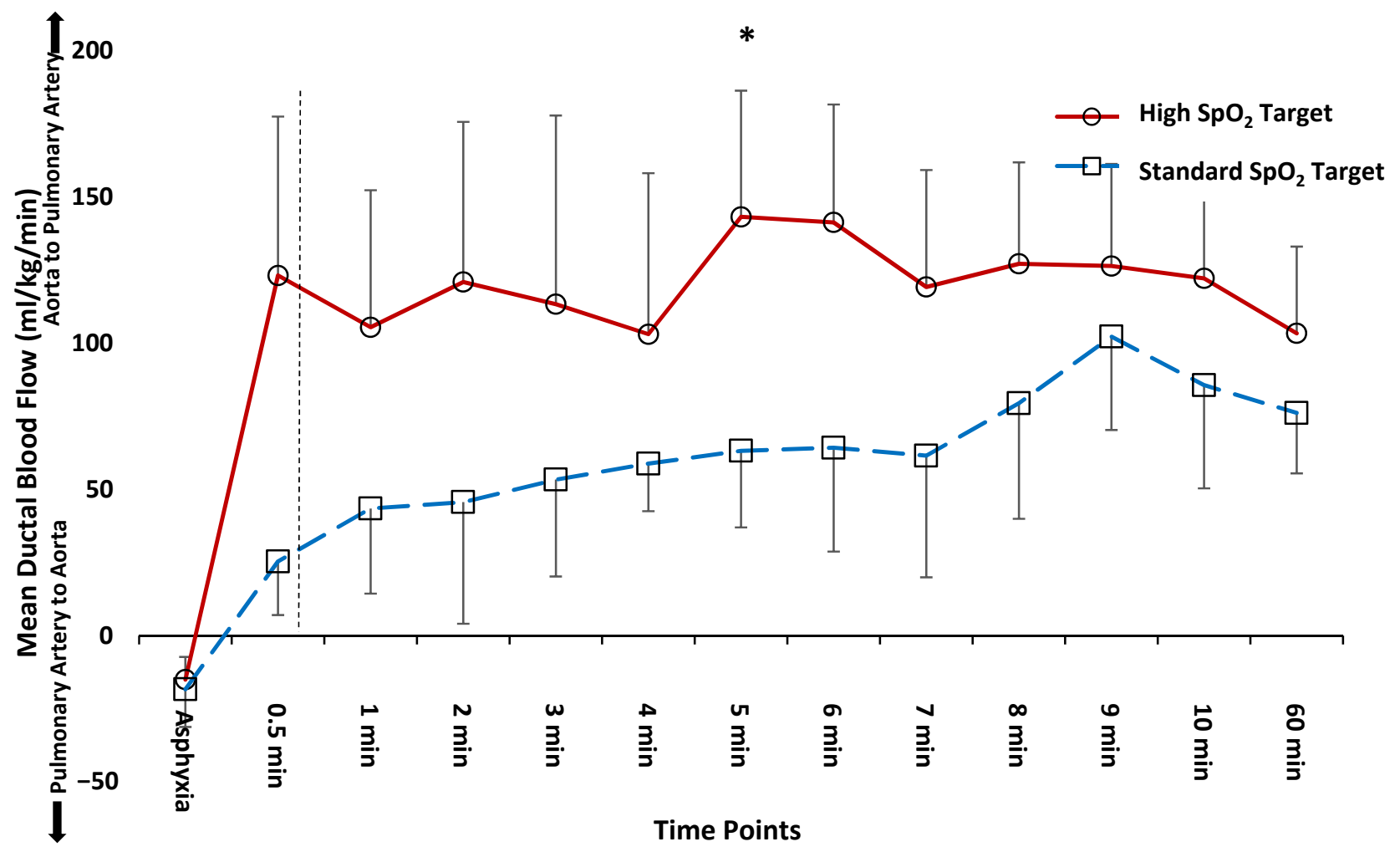

Figure 1. Mean ductus arteriosus blood flow ( $Q_{\mathrm{DA}}$ ) and direction of flow over timepoints from asphyxia, $0.5 \mathrm{~min}$ and up to $60 \mathrm{~min}$ after delivery between the two oxygen target groups. Delivery of lamb is indicated by the dashed, vertical line. Positive flow indicates left-to-right shunting from aorta to the pulmonary artery. Negative flow indicates right-to-left shunting 
from pulmonary artery to the aorta. Median (interquartile range) time for exclusive left-to-right ductal shunting post-delivery was significantly shorter in the high $\mathrm{SpO}_{2}$ target group (median 7.4 vs. $31.5 \mathrm{~min}$, by Wilcoxon rank sum test). ${ }^{*} p<0.05$, left-to-right ductal flow was significantly higher with high $\mathrm{SpO}_{2}$ target compared to standard $\mathrm{SpO}_{2}$ target $(p=0.002$, ANOVA repeated measures). However, by $60 \mathrm{~min}$ after delivery, the $\mathrm{QDA}_{\mathrm{DA}}$ was not different between the two $\mathrm{SpO}_{2}$ targets. The QDA significantly increased in both high and standard $\mathrm{SpO}_{2}$ targets from fetal baseline to 5-min after birth, and significantly decreased by 60 min after birth in the high $\mathrm{SpO}_{2}$ target.

\subsection{Comparison of Hemodynamics and Arterial Blood Gas Parameters at 5 and 10 min after Birth}

During the first 10 min after delivery, the $\mathrm{Q}_{\mathrm{DA}}$ (left-to-right, Figure 1, $p=0.002$ ) and $\mathrm{Q}_{\mathrm{PA}}$ (Figure 2, $p=0.048$ ) were significantly higher with high $\mathrm{SpO}_{2}$ target compared to standard $\mathrm{SpO}_{2}$ target by ANOVA repeated measures. The $\mathrm{Q}_{\mathrm{PA}}$ significantly decreased from 5-min to 60-min after birth with high $\mathrm{SpO}_{2}$ target. The hemodynamic parameters at $5 \mathrm{~min}$ and at 10 min time points after delivery are depicted in Tables 2 and 3 respectively and were not different. The arterial blood gas parameters were not different at 10-min after delivery (Table 3). Although the $\mathrm{PaO}_{2}$ and $\mathrm{SpO}_{2}$ were higher in the high $\mathrm{SpO}_{2}$ target group, these differences did not reach statistical significance.

Table 2. Comparison of hemodynamics at 5 min after birth in a perinatal lamb model of MAS and PPHN.

\begin{tabular}{ccc}
\hline Parameter & Standard $\mathbf{S p O}_{\mathbf{2}}$ Target (85-94\%, $\mathbf{n = 6}$ ) & High SpO $_{\mathbf{2}}$ Target (95-99\%, $\left.\mathbf{n}=\mathbf{6}\right)$ \\
\hline Heart Rate $(\mathrm{bpm})$ & $182.12 \pm 12.14$ & $170.78 \pm 13.08$ \\
Mean Arterial Blood Pressure $(\mathrm{mm} \mathrm{Hg})$ & $52.91 \pm 18.79$ & $65.38 \pm 8.81$ \\
Mean Carotid Flow $\left(\mathrm{Q}_{\mathrm{CA}}, \mathrm{mL} / \mathrm{kg} / \mathrm{min}\right)$ & $34.10 \pm 14.84$ & $20.22 \pm 8.47$ \\
\hline
\end{tabular}

Data presented as mean and standard deviation. Positive flow indicates left-to-right ductus arteriosus blood flow. There was no significant difference between the two $\mathrm{SpO}_{2}$ targets at 5 -min timepoint by unpaired $t$-test.

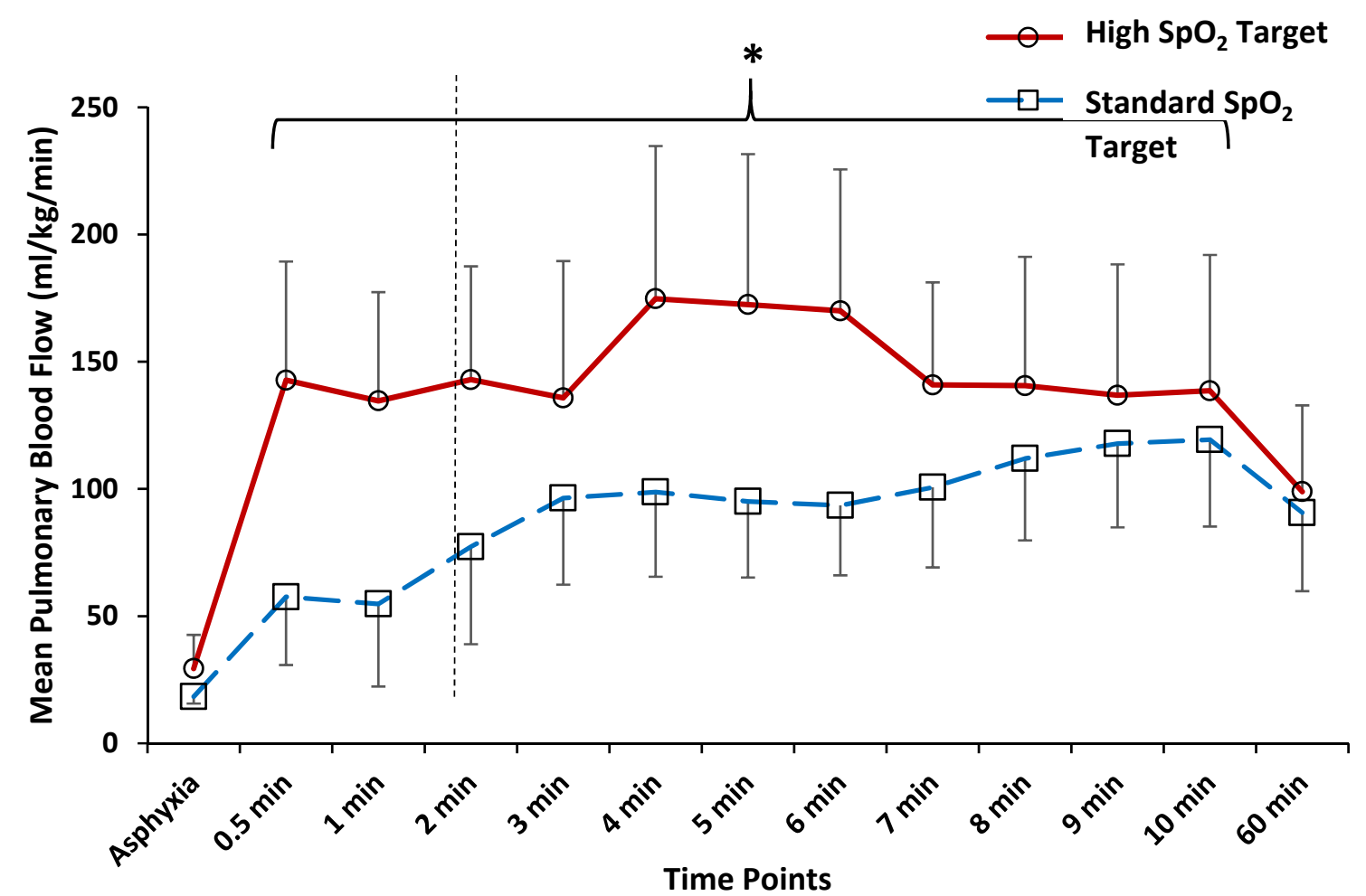

Figure 2. Mean pulmonary blood flow (QPA $)$ during the immediate post-natal period in a lamb model of meconium aspiration syndrome (MAS) and persistent pulmonary hypertension (PPHN). Delivery of lamb is indicated by the dashed, vertical line. The $\mathrm{Q}_{\mathrm{PA}}$ was significantly higher from $0.5 \mathrm{~min}$ to $10 \mathrm{~min}$ after delivery with high $\mathrm{SpO}_{2}$ target compared to standard $\mathrm{SpO}_{2}$ target $(p=0.048)$. However, by $60 \mathrm{~min}$ after delivery, the $\mathrm{Q}_{\mathrm{PA}}$ was not different between the two $\mathrm{SpO}_{2}$ targets. ${ }^{*} p<0.05$. 
Table 3. Comparison of hemodynamics and oxygenation at $10 \mathrm{~min}$ after birth in a perinatal lamb model of MAS and PPHN.

\begin{tabular}{|c|c|c|}
\hline Parameter & Standard $\mathrm{SpO}_{2}$ Target $(85-94 \%, \mathrm{n}=6)$ & High $\mathrm{SpO}_{2}$ Target $(95-99 \%, \mathrm{n}=6)$ \\
\hline Hemoglobin, g/dL & $13.18 \pm 1.95$ & $11.9 \pm 1.40$ \\
\hline $\mathrm{pH}$ & $7.05 \pm 0.24$ & $7.11 \pm 0.19$ \\
\hline $\mathrm{PaCO}_{2}(\mathrm{~mm} \mathrm{Hg})$ & $79.48 \pm 48.89$ & $64.5 \pm 42.89$ \\
\hline $\mathrm{PaO}_{2}(\mathrm{~mm} \mathrm{Hg})$ & $53.42 \pm 22.97$ & $60.13 \pm 2.55$ \\
\hline $\mathrm{SaO}_{2}(\%)$ & $89.7 \pm 4.32$ & $93.9 \pm 3.96$ \\
\hline $\mathrm{SpO}_{2}(\%)$ & $77.75 \pm 30.61$ & $91.33 \pm 6.51$ \\
\hline $\mathrm{CaO}_{2}\left(\mathrm{~mL} \mathrm{O}_{2} / \mathrm{dL}\right)$ & $15.98 \pm 2.14$ & $15.14 \pm 1.62$ \\
\hline Cerebral Oxygen Delivery (mL/kg/min) & $4.78 \pm 2.23$ & $3.69 \pm 0.47$ \\
\hline Lactate $(\mathrm{mmol} / \mathrm{L})$ & $6.02 \pm 1.97$ & $5.90 \pm 1.75$ \\
\hline Heart Rate (bpm) & $176.0 \pm 13.22$ & $162.55 \pm 31.18$ \\
\hline Mean Arterial Blood Pressure (mmHg) & $59.34 \pm 9.497$ & $65.67 \pm 8.98$ \\
\hline Mean Carotid Flow $\left(\mathrm{Q}_{\mathrm{CA}}, \mathrm{mL} / \mathrm{kg} / \mathrm{min}\right)$ & $29.17 \pm 12.31$ & $20.44 \pm 7.32$ \\
\hline Inspired $\mathrm{O}_{2}(\%)$ at $10 \mathrm{~min}$ & $40.75 \pm 39.5$ & $30.67 \pm 16.74$ \\
\hline
\end{tabular}

Data presented as mean and standard deviation. No significant differences in parameters between the standard and high $\mathrm{SpO}_{2}$ target groups at 10-min time point by unpaired $t$-test.

\subsection{Comparison of Hemodynamics and Arterial Blood Gas Parameters at 60 min after Birth}

There was no significant difference in mean $\mathrm{Q}_{\mathrm{CA}}, \mathrm{Q}_{\mathrm{DA}}$, or $\mathrm{Q}_{\mathrm{PA}}$ blood flows at $60 \mathrm{~min}$ after birth (Table 4). One lamb randomized in the standard $\mathrm{SpO}_{2}$ group maintained a bidirectional $\mathrm{Q}_{\mathrm{DA}}$ shunt throughout the study period. There were no significant differences in inspired $\mathrm{O}_{2}$ concentration, arterial $\mathrm{O}_{2}$ content, cerebral $\mathrm{O}_{2}$ delivery or $\mathrm{PaO}_{2}$ between the standard and high $\mathrm{SpO}_{2}$ target groups at $60 \mathrm{~min}$ after birth. However, the $\mathrm{pH}$ was higher ( $p=0.046)$ and $\mathrm{PaCO}_{2}$ was lower $(p=0.042)$ with high $\mathrm{SpO}_{2}$ target at the 60 min timepoint.

An illustration summarizing the hemodynamics and gas exchange at 60 min after birth is presented as Figure 3A,B.

Table 4. Comparison of hemodynamics and oxygenation comparisons at $60 \mathrm{~min}$ after birth in a perinatal lamb model of MAS and PPHN.

\begin{tabular}{|c|c|c|}
\hline Parameter & Standard $\mathrm{SpO}_{2}$ Target $(85-94 \%, \mathrm{n}=6)$ & High $\mathrm{SpO}_{2}$ Target $(95-99 \%, \mathrm{n}=6)$ \\
\hline Hemoglobin, g/dL & $12.32 \pm 3.17$ & $11.85 \pm 1.08$ \\
\hline $\mathrm{pH}$ & $7.12 \pm 0.11$ & $7.25 \pm 0.09 \neq$ \\
\hline $\mathrm{PaCO}_{2}(\mathrm{mmHg})$ & $61.23 \pm 15.42$ & $44.08 \pm 7.07^{\ddagger}$ \\
\hline $\mathrm{PaO}_{2}(\mathrm{mmHg})$ & $48.14 \pm 21.76$ & $65.08 \pm 18.77$ \\
\hline $\mathrm{SaO}_{2}(\%)$ & $86.66 \pm 12.29$ & $94.68 \pm 3.55$ \\
\hline $\mathrm{SpO}_{2}(\%)$ & $88.4 \pm 7.3$ & $95.33 \pm 2.50$ \\
\hline $\mathrm{CaO}_{2}\left(\mathrm{mlO}_{2} / \mathrm{dL}\right)$ & $14.96 \pm 4.22$ & $15.23 \pm 1.44$ \\
\hline Cerebral Oxygen Delivery $(\mathrm{ml} / \mathrm{kg} / \mathrm{min})$ & $2.54 \pm 0.68$ & $2.12 \pm 0.9$ \\
\hline Lactate $(\mathrm{mmol} / \mathrm{L})$ & $4.25 \pm 1.94$ & $4.07 \pm 1.75$ \\
\hline Heart Rate (bpm) & $167.76 \pm 32.46$ & $154.56 \pm 9.94$ \\
\hline Mean Arterial Blood Pressure (mmHg) & $53.41 \pm 14.30$ & $71.51 \pm 8.14^{\ddagger}$ \\
\hline Mean Carotid Flow ( $\left.\mathrm{Q}_{\mathrm{CA}}-\mathrm{mL} / \mathrm{kg} / \mathrm{min}\right)$ & $16.01 \pm 4.96$ & $14.28 \pm 7.21$ \\
\hline Inspired $\mathrm{O}_{2}(\%)$ at $60 \mathrm{~min}$ & $41.5 \pm 13.25$ & $64.66 \pm 31.51$ \\
\hline
\end{tabular}

$\mathrm{PaCO}_{2}=$ arterial carbon dioxide pressure; $\mathrm{PaO}_{2}=$ arterial oxygen pressure; $\mathrm{SaO}_{2}=$ arterial oxygen saturation from blood gas; $\mathrm{SpO}_{2}=$ preductal pulse oximeter oxygen saturation; $\mathrm{CaO}_{2}=$ arterial oxygen content. ${ }^{\ddagger}$ Significantly different from the $85-94 \%$ target group; $p<0.05$, unpaired student $t$-test, unequal variances. 


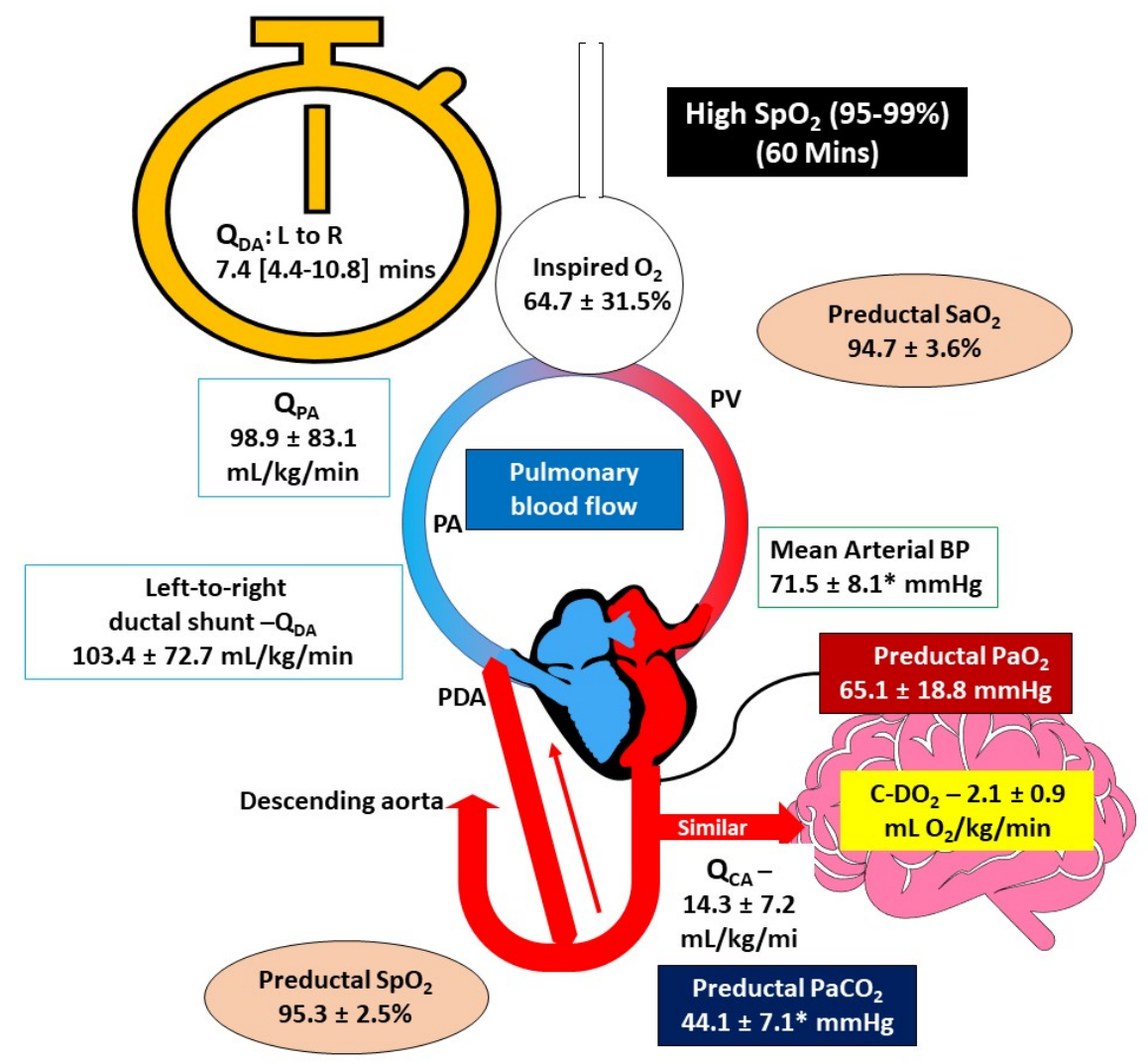

(A)

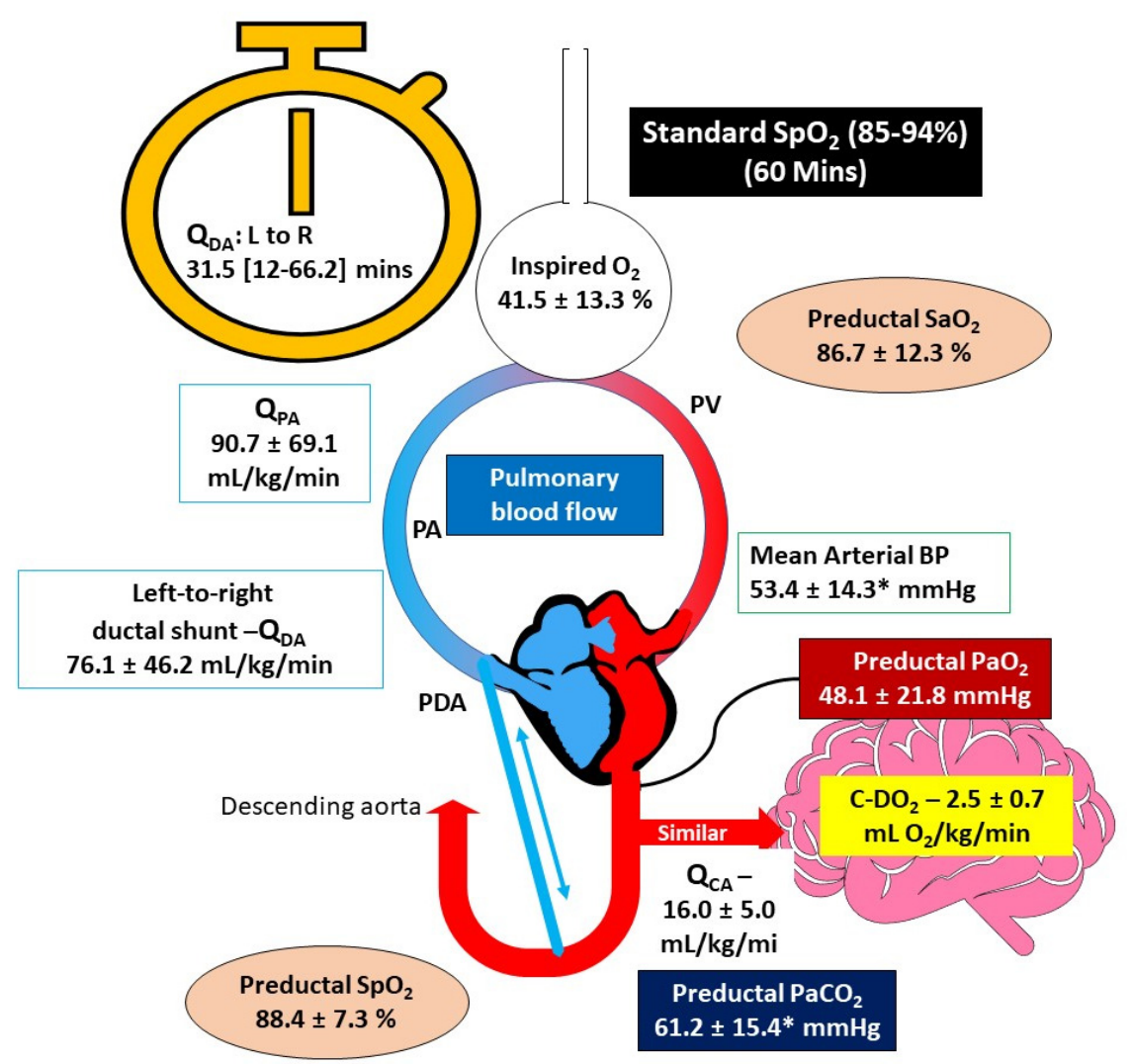

(B)

Figure 3. (A) Graphical summary of the results demonstrating the hemodynamics and gas exchange at 60 min after birth with high (95-99\%) oxygen saturation $\left(\mathrm{SpO}_{2}\right)$ targets in an ovine model of meconium 
aspiration and pulmonary hypertension. Median time to reversal of shunting was 7.4 (4.4-10.8) min after birth. The inspired oxygen concentration, preductal $\mathrm{SpO}_{2}$ and arterial oxygen saturation $\left(\mathrm{SaO}_{2}\right)$, left-to-right ductal shunting $\left(\mathrm{Q}_{\mathrm{DA}}\right)$, left pulmonary artery blood flow $\left(\mathrm{Q}_{\mathrm{PA}}\right)$, left carotid artery blood flow $\left(\mathrm{Q}_{\mathrm{CA}}\right)$, cerebral $\mathrm{O}_{2}$ delivery $\left(\mathrm{C}-\mathrm{DO}_{2}\right)$ and arterial partial pressure of carbon dioxide $\left(\mathrm{PaCO}_{2}\right)$ are shown. Shorter time to reversal of $\mathrm{Q}_{\mathrm{DA}}$ shunt to left-to-right, transiently increased $\mathrm{Q}_{\mathrm{DA}}$ and $\mathrm{Q}_{\mathrm{PA}}$ from $0.5-10 \mathrm{~min}$ after birth, and lower $\mathrm{PaCO}_{2}$ at $60 \mathrm{~min}$ were observed with high $\mathrm{SpO}_{2}$ target. ${ }^{*} p<0.05$ compared to standard $\mathrm{SpO}_{2}$ target group in (B). (B) Graphical summary of the results demonstrating the hemodynamics and gas exchange at $60 \mathrm{~min}$ after birth with standard (85-94\%) oxygen saturation $\left(\mathrm{SpO}_{2}\right)$ targets in an ovine model of meconium aspiration and pulmonary hypertension. Median time to reversal of shunting was 31.5 (12-66.2) min after birth. The inspired oxygen concentration, preductal $\mathrm{SpO}_{2}$ and arterial oxygen saturation $\left(\mathrm{SaO}_{2}\right)$, left-to-right ductal shunting $\left(\mathrm{Q}_{\mathrm{DA}}\right)$, left pulmonary artery blood flow $\left(\mathrm{Q}_{\mathrm{PA}}\right)$, left carotid artery blood flow $\left(\mathrm{Q}_{\mathrm{CA}}\right)$, cerebral $\mathrm{O} 2$ delivery $\left(\mathrm{C}-\mathrm{DO}_{2}\right)$ and arterial partial pressure of carbon dioxide $\left(\mathrm{PaCO}_{2}\right)$ are shown. Longer time to reversal of $\mathrm{Q}_{\mathrm{DA}}$ shunt to left-to-right and higher $\mathrm{PaCO}_{2}$ at $60 \mathrm{~min}$ were observed with standard $\mathrm{SpO}_{2}$ target. ${ }^{*} p<0.05$ compared to high $\mathrm{SpO}_{2}$ target group shown in (A).

\section{Discussion}

Neonatal PPHN is commonly associated with parenchymal lung disease such as MAS [1]. Mortality rates of $4-33 \%$ have been reported for neonatal PPHN [12]. Rightto-left shunting via the PDA and PFO resulting in labile hypoxemia is characteristic of PPHN. Supplemental $\mathrm{O}_{2}$ can decrease PVR thus improving $\mathrm{Q}_{\mathrm{PA}}$, hastening reversal of extrapulmonary shunting to left-to-right. We demonstrate quicker reversal of ductal shunting to left-to-right with higher (95-99\%) compared to the lower (85-94\%) $\mathrm{SpO}_{2}$ target during resuscitation and in the post-resuscitation period.

The American Academy of Pediatrics (AAP) NRP Textbook of Neonatal Resuscitation recommends initiating resuscitation with $21 \% \mathrm{O}_{2}$, titrating inspired $\mathrm{O}_{2}$ to achieve the target $\mathrm{SpO}_{2}$ range for every minute, and finally $85-95 \%$ by 10 min after birth. Maintaining $\mathrm{SpO}_{2}$ within the range recommended by NRP by actively titrating the inspired $\mathrm{O}_{2}$ led to effective oxygenation and $\mathrm{Q}_{\mathrm{PA}}$ in an ovine model of MAS [4]. However, there is wide variation among neonatologists in their preference of $\mathrm{SpO}_{2}$ targets immediately after the initial resuscitation period $[13,14]$. In a recent animal study by Rawat et al., higher $\mathrm{SpO}_{2}$ target of 95-99\% resulted in lower PVR, higher $\mathrm{Q}_{\mathrm{PA}}$, higher cerebral $\mathrm{O}_{2}$ delivery with lower lactate levels, but was associated with higher inspired $\mathrm{O}_{2}$ and higher lung 3-nitrotyrosine, a marker of oxidative stress compared to lower ranges of target $\mathrm{SpO}_{2}$ [5]. However, the authors did not evaluate direction of ductal flow and $\mathrm{Q}_{\mathrm{DA}}$ in that study.

During neonatal resuscitation, $\mathrm{O}_{2}$ needs to be titrated judiciously to avoid hypo or hyperoxia. Kapadia et al. reported that post-resuscitation hyperoxia with perinatal acidemia is associated with higher incidence of moderate to severe hypoxic ischemic encephalopathy [15]. Thus, it is prudent to decrease supplemental $\mathrm{O}_{2}$ in a timely manner to avoid hyperoxemia. We show that the benefits of targeting higher $\mathrm{SpO}_{2}$ are transient and $\mathrm{Q}_{\mathrm{PA}}$ is identical between the two study groups by $60 \mathrm{~min}$ after birth. We also observed lower $\mathrm{PaCO}_{2}$ in the high $\mathrm{SpO}_{2}$ target group at $60 \mathrm{~min}$ after birth. We speculate that the higher $\mathrm{SpO}_{2}$ target may have caused a transient surge in $\mathrm{Q}_{\mathrm{PA}}$ (Figure 2) that might have contributed to better gas exchange and lower $\mathrm{PaCO}_{2}$ (Figure 3A,B). Additionally, the initial increase in left-to-right $Q_{\mathrm{DA}}$ and increase in $\mathrm{Q}_{\mathrm{PA}}$ were not persistent at $60 \mathrm{~min}$ after birth (Figures 1 and 2). We speculate that reduction in $\mathrm{Q}_{\mathrm{PA}}$ could be secondary to transient effect of increased inspired $\mathrm{O}_{2}$ on PVR or ductal constriction limiting QDA leading to lower $Q_{P A}$. As the ductal flow remained steady between $5 \mathrm{~min}$ and $60 \mathrm{~min}$ after birth (Figure 1), we suspect that the PDA remained patent at $60 \mathrm{~min}$ in these lambs. We speculate that higher $\mathrm{SpO}_{2}$ target is associated with earlier ductal narrowing and less cardiac dysfunction with quicker cardiovascular recovery from the asphyxial insult resulting in better mean arterial pressures (MAPs). Whereas in the standard $\mathrm{SpO}_{2}$ target group, there may be slower ductal constriction and cardiovascular recovery from the asphyxial insult resulting 
in lower MAPs. Higher volume of shunt from the aorta-to-pulmonary artery is likely to expose ductal tissue to higher $\mathrm{PaO}_{2}$ and hasten narrowing of the ductus. Furthermore, the diastolic $\mathrm{BP}$ were higher with high $\mathrm{SpO}_{2}$ target at 60 min after delivery when compared to standard $\mathrm{SpO}_{2}$ target (65 \pm 13 vs. $45 \pm 6, p=0.02$ ), possibly due to ductal constriction, thus contributing to higher MAPs.

Our study has several limitations. The severity of asphyxia was mild to moderate. Despite this, we did demonstrate significant degree of hypoxemia, low $\mathrm{Q}_{\mathrm{PA}}$ and rightto-left shunting across the PDA following delivery in all the lambs (Tables 1 and 2 and Figure 1). We did not measure the pulmonary artery and left atrial pressures, and hence could not evaluate the PVR. In addition, we did not evaluate the shunting across the PFO. We had a small sample size and larger number of lambs might have led to different results. The markers of oxidative stress have not been evaluated. We did not recover the lambs and assess for long term outcomes. Although we targeted to achieve preductal $\mathrm{SpO}_{2}$ within a narrow set range, the achieved $\mathrm{SpO}_{2}$ was $88 \pm 7 \%$ and $95 \pm 3 \%$ in the standard and high $\mathrm{SpO}_{2}$ target groups, respectively. This difficulty in achieving a set $\mathrm{SpO}_{2}$ target range has previously been demonstrated in randomized trials in preterm infants $[16,17]$.

To our knowledge, this is the first comparison of time to reversal of ductal shunting in PPHN between standard and high $\mathrm{SpO}_{2}$ targets during resuscitation and in the postresuscitation period. The novel aspect of this study is the measurement of $\mathrm{Q}_{\mathrm{DA}}$ along with the direction of flow in a large mammalian model of MAS and PPHN closely mimicking human cardiopulmonary physiology. The lambs underwent meconium aspiration by spontaneous aspiration with negative pressure in the perinatal period during transition rather forceful instillation of meconium in the postnatal (1-3 days, often the case in piglet models) period [18]. Although an ovine model of PPHN can be induced by prenatal ductal ligation, we are unable to assess $\mathrm{Q}_{\mathrm{DA}}$ in that model. Finally, the randomized study design is a major strength of this study.

\section{Conclusions}

In this term lamb model of MAS and PPHN, targeting $\mathrm{SpO}_{2}$ at a higher range (95-99\%) during resuscitation and in the immediate post-resuscitation period, led to a quicker transition to left-to-right shunting across the PDA but did not result in sustained increase in pulmonary blood flow. These findings support the current NRP recommendations to target preductal $\mathrm{SpO}_{2}$ between $85-95 \%$ by $10 \mathrm{~min}$. Clinical trials evaluating hemodynamics and long-term neurocognitive outcomes in term neonates comparing current recommended range to higher $\mathrm{SpO}_{2}$ targets are warranted in patients at risk of PPHN such as MAS with asphyxia and congenital diaphragmatic hernia.

Author Contributions: A.L.L.: data extraction and analysis, conducting experiments, and writing the manuscript. P.V.: conducting experiments, critiquing, and revising the manuscript. M.E.H.: conducting experiments, data extraction, critiquing and revising the manuscript. S.L.: concept, procuring funds, conducting experiments, writing, critiquing, and revising the manuscript. D.S.: conducting studies, analysis of data, writing, critiquing and revising the manuscript. All authors have read and agreed to the published version of the manuscript.

Funding: This research was funded by NICHD 5R01 HD072929 (S.L.), Children's Miracle Network at University of California, Davis, First Tech Federal Credit Union and UC Davis Pediatrics, and Canadian Pediatric Society NRP research grant (D.S.).

Institutional Review Board Statement: The study was conducted according to the guidelines of the Declaration of Helsinki and approved by the Institutional Animal Care and Use Committee (IACUC) at the University of California Davis, Davis, CA, USA (protocol \#20267).

Informed Consent Statement: Not applicable.

Data Availability Statement: The data presented in this study are available in this article.

Conflicts of Interest: The authors declare no conflict of interest. S.L. is a member of the AAP NRP steering committee. The views expressed in this article are his own and does not represent the official 
position of AAP or NRP. The funders had no role in the design of the study; in the collection, analyses, or interpretation of data; in the writing of the manuscript, or in the decision to publish the results.

\section{References}

1. Lakshminrusimha, S.; Keszler, M. Persistent Pulmonary Hypertension of the Newborn. Neoreviews 2015, 16, e680-e692. [CrossRef] [PubMed]

2. Morin, F.C., 3rd; Egan, E.A.; Ferguson, W.; Lundgren, C.E. Development of pulmonary vascular response to oxygen. Am. J. Physiol. Heart Circ. Physiol. 1988, 254, H542-H546. [CrossRef] [PubMed]

3. Teitel, D.F.; Iwamoto, H.S.; Rudolph, A.M. Changes in the Pulmonary Circulation during Birth-Related Events. Pediatr. Res. 1990, 27, 372-378. [CrossRef] [PubMed]

4. Rawat, M.; Chandrasekharan, P.K.; Swartz, D.D.; Mathew, B.; Nair, J.; Gugino, S.F.; Koenigsknecht, C.; Vali, P.; Lakshminrusimha, S Neonatal resuscitation adhering to oxygen saturation guidelines in asphyxiated lambs with meconium aspiration. Pediatr. Res. 2016, 79, 583-588. [CrossRef] [PubMed]

5. Rawat, M.; Chandrasekharan, P.; Gugino, S.F.; Koenigsknecht, C.; Nielsen, L.; Wedgwood, S.; Mathew, B.; Nair, J.; Steinhorn, R.; Lakshminrusimha, S. Optimal Oxygen Targets in Term Lambs with Meconium Aspiration Syndrome and Pulmonary Hypertension. Am. J. Respir. Cell Mol. Biol. 2020, 63, 510-518. [CrossRef] [PubMed]

6. Smolich, J.J.; Kenna, K.R.; Mynard, J.P. Antenatal betamethasone augments early rise in pulmonary perfusion at birth in preterm lambs: Role of ductal shunting and right ventricular outflow distribution. Am. J. Physiol. Regul. Integr. Comp. Physiol. 2019, 316, R716-R724. [CrossRef] [PubMed]

7. Lakshminrusimha, S.; Mathew, B.; Nair, J.; Gugino, S.F.; Koenigsknecht, C.; Rawat, M.; Nielsen, L.; Swartz, D.D. Tracheal suctioning improves gas exchange but not hemodynamics in asphyxiated lambs with meconium aspiration. Pediatr. Res. 2015, 77, 347-355. [CrossRef] [PubMed]

8. Kilkenny, C.; Browne, W.J.; Cuthill, I.C.; Emerson, M.; Altman, D.G. Improving bioscience research reporting: The ARRIVE guidelines for reporting animal research. PLoS Biol. 2010, 8, e1000412. [CrossRef] [PubMed]

9. Sankaran, D.; Chandrasekharan, P.K.; Gugino, S.F.; Koenigsknecht, C.; Helman, J.; Nair, J.; Mathew, B.; Rawat, M.; Vali, P.; Nielsen, L.; et al. Randomised trial of epinephrine dose and flush volume in term newborn lambs. Arch. Dis. Child. Fetal Neonatal Ed. 2021. [CrossRef] [PubMed]

10. Sankaran, D.; Vali, P.; Chen, P.; Lesneski, A.L.; Hardie, M.E.; Alhassen, Z.; Wedgwood, S.; Wyckoff, M.H.; Lakshminrusimha, S. Randomized trial of oxygen weaning strategies following chest compressions during neonatal resuscitation. Pediatr. Res. 2021, 1-9. [CrossRef]

11. American Academy of Pediatrics; Weiner, G.M.; American Heart Association; Zaichkin, J. Textbook of Neonatal Resuscitation, 7th ed.; American Academy of Pediatrics: Itasca, IL, USA, 2016.

12. Walsh-Sukys, M.C.; Tyson, J.E.; Wright, L.L.; Bauer, C.R.; Korones, S.B.; Stevenson, D.K.; Verter, J.; Stoll, B.J.; Lemons, J.A.; Papile, L.A.; et al. Persistent pulmonary hypertension of the newborn in the era before nitric oxide: Practice variation and outcomes. Pediatrics 2000, 105, 14-20. [CrossRef] [PubMed]

13. Nakwan, N.; Chaiwiriyawong, P. An international survey on persistent pulmonary hypertension of the newborn: A need for an evidence-based management. J. Neonatal-Perinat. Med. 2016, 9, 243-250. [CrossRef] [PubMed]

14. Alapati, D.; Jassar, R.; Shaffer, T.H. Management of Supplemental Oxygen for Infants with Persistent Pulmonary Hypertension of Newborn: A Survey. Am. J. Perinatol. 2017, 34, 276-282. [CrossRef] [PubMed]

15. Kapadia, V.S.; Chalak, L.F.; DuPont, T.L.; Rollins, N.K.; Brion, L.P.; Wyckoff, M.H. Perinatal asphyxia with hyperoxemia within the first hour of life is associated with moderate to severe hypoxic-ischemic encephalopathy. J. Pediatr. 2013, 163, 949-954. [CrossRef] [PubMed]

16. Askie, L.M.; Darlow, B.A.; Finer, N.; Schmidt, B.; Stenson, B.; Tarnow-Mordi, W.; Davis, P.G.; Carlo, W.A.; Brocklehurst, P.; Davies, L.C.; et al. Association Between Oxygen Saturation Targeting and Death or Disability in Extremely Preterm Infants in the Neonatal Oxygenation Prospective Meta-analysis Collaboration. JAMA 2018, 319, 2190-2201. [CrossRef] [PubMed]

17. Lakshminrusimha, S.; Manja, V.; Mathew, B.; Suresh, G.K. Oxygen targeting in preterm infants: A physiological interpretation. J. Perinatol. 2015, 35, 8-15. [CrossRef] [PubMed]

18. Wiswell, T.E.; Peabody, S.S.; Davis, J.M.; Slayter, M.V.; Bent, R.C.; Merritt, T.A. Surfactant therapy and high-frequency jet ventilation in the management of a piglet model of the meconium aspiration syndrome. Pediatr. Res. 1994, 36, 494-500. [CrossRef] [PubMed] 